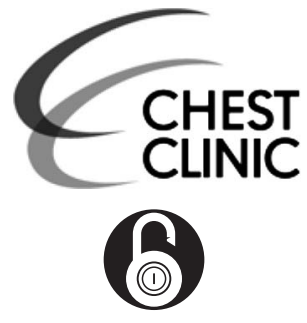

\section{OPEN ACCESS}

${ }^{1}$ Department of Cardiology, University of Bonn, Bonn, Germany

${ }^{2}$ Department of Nuclear Medicine, University of Bonn, Bonn, Germany

\section{Correspondence to} Dr René Andrié, Department of Internal Medicine II-

Cardiology/Pneumology, University of Bonn, SigmundFreud-Str. 25, Bonn 53105, Germany; Rene.Andrie@ukb. uni-bonn.de

Received 15 July 2016 Revised 25 August 2016 Accepted 26 August 2016 Published Online First 5 December 2016

\title{
Prevention of sudden cardiac death by the wearable cardioverter defibrillator in a young patient with cardiac sarcoidosis
}

\author{
René Andrié, ${ }_{1}^{1}$ Florian C Gaertner, ${ }^{2}$ Dirk Skowasch ${ }^{1}$
}

Patients with sarcoidosis with cardiac manifestation have a worse prognosis due to sudden cardiac death. The most important predictor of survival appears to be left ventricular function. ${ }^{1} \mathrm{~A}$ 25 -year-old female patient was transferred to our hospital. Initial echocardiography demonstrated a reduced ejection fraction (EF) of 30\%. Based on CT scan, a diagnosis of cardiac sarcoidosis was suspected. This was proven by transbronchial biopsy. As a novel method, macrophage-directed positron emission tomography (PET)/CT using the somatostatin receptor ligand ${ }^{68} \mathrm{Ga}$-DOTA-TOC was used to image active inflammation in the thorax. Potential advantages of ${ }^{68} \mathrm{Ga}-\mathrm{DOTA}-\mathrm{TOC}$ over ${ }^{18}$ F-FDG are a lower radiation exposure and a simplified and less artefact-prone imaging procedure as elaborate patient preparation protocols suppressing physiologic myocardial glucose uptake are not needed with ${ }^{68} \mathrm{Ga}$-DOTA-TOC. Areas of abnormally increased tracer uptake consistent with inflammatory changes were observed both in the lung (figure 1A) and in the left ventricle (figure 1C). Corticoid treatment and heart failure medication were initiated leading to a rapid clinical improvement, accompanied by an increase in EF $(45 \%)$ and reduction in inflammation as seen in the follow-up by ${ }^{68} \mathrm{Ga}$-DOTA-TOC 4 months later (figure 1B,D). In anticipation of an improvement of $\mathrm{EF}$, the patient was equipped with the wearable cardioverter defibrillator (WCD, LifeVest system, Zoll) to protect against sudden cardiac death. This allowed insertion of an implantable cardioverter defibrillator (ICD) to be deferred. One day after discharge, the patient presented with symptomatic sustained ventricular tachycardia, that was detected and terminated by one shock (figure 1E). Despite

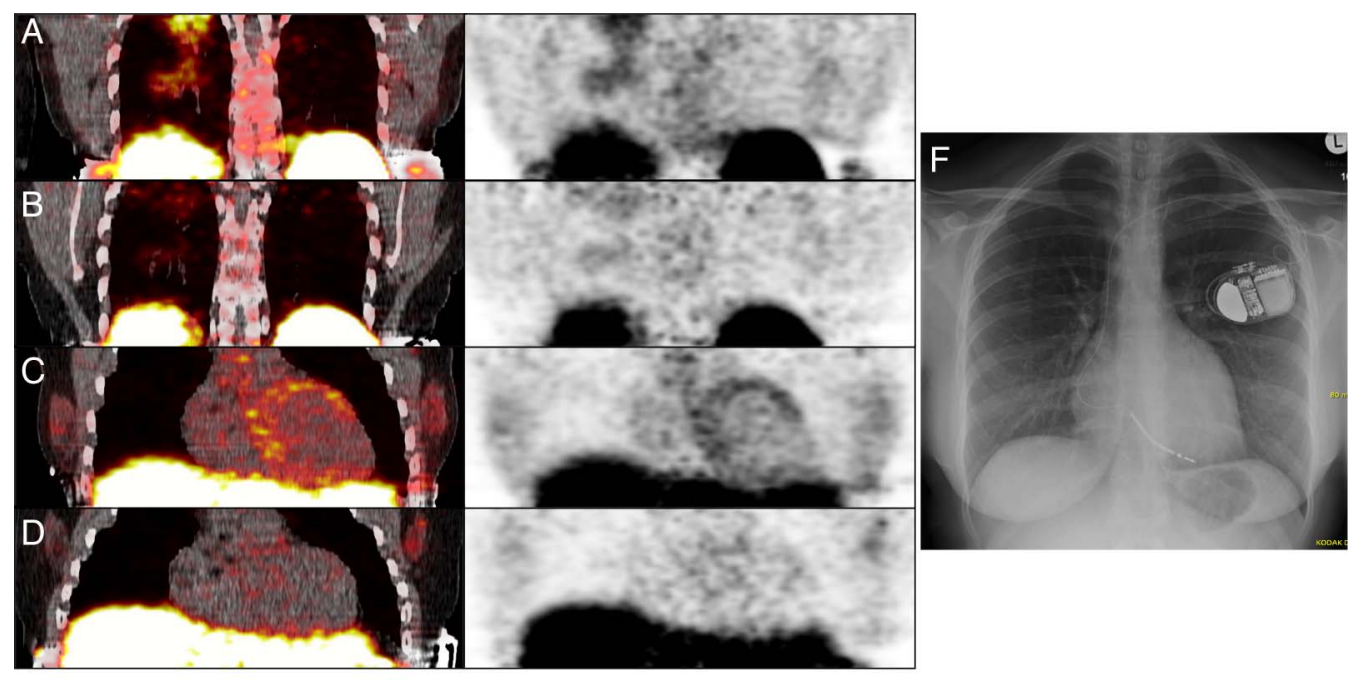

$\mathrm{E}$

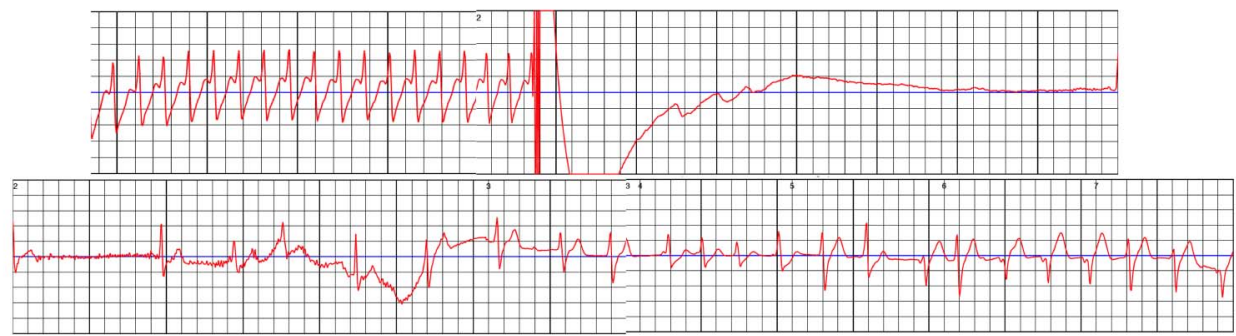

CrossMark

To cite: Andrié $R$,

Gaertner FC, Skowasch D.

Thorax 2017;72:286-287.
Figure 1 Positron emission tomography (PET)/CT using somatostatin receptor ligand ( ${ }^{68} \mathrm{Ga}$-DOTA-TOC) shows areas of abnormally increased tracer uptake consistent with inflammatory changes both in the lung $(A)$ and in the left ventricle (C). Reduction in inflammation in the follow-up PET/CT 4 months later after corticoid treatment (B and D). Sustained ventricular tachycardia documented and terminated by shock from the wearable cardioverter defibrillator (E). Chest X-ray after implantation of a single chamber implantable cardioverter defibrillator (F). 
improvement of EF and no further ventricular arrhythmias after 8 weeks as shown by the LifeVest Network, the patient finally decided on a permanent ICD placement (figure $1 \mathrm{~F}$ ). The Heart Rhythm Society (HRS) consensus statement states that an ICD implantation 'is recommended' in case of spontaneous sustained ventricular arrhythmias, prior cardiac arrest, or EF $\leq 35 \%$ despite optimal medical therapy and a period of immunosuppression (class I recommendation). ${ }^{1}$ The document states that an ICD 'can be useful' (class II recommendation) where: permanent pacemaker implantation is indicated, there is unexplained syncope, or inducible sustained ventricular arrhythmias (IIa), or an EF between $36 \%$ and $49 \%$ despite optimal medical therapy for heart failure and a period of immunosuppression (IIb). This case illustrates for the first time that the WCD provides an efficient device in a patient with cardiac sarcoidosis.

Competing interests None declared.

Provenance and peer review Not commissioned; externally peer reviewed.

Open Access This is an Open Access article distributed in accordance with the Creative Commons Attribution Non Commercial (CC BY-NC 4.0) license, which permits others to distribute, remix, adapt, build upon this work non-commercially, and license their derivative works on different terms, provided the original work is properly cited and the use is non-commercial. See: http://creativecommons.org/ licenses/by-nc/4.0/

\section{REFERENCE}

1 Birnie DH, Sauer WH, Bogun F, et al. HRS Expert consensus statement on the diagnosis and management of arrhythmias associated with cardiac sarcoidosis. Heart Rhythm 2014;7:1305-23. 